\title{
Af- en opsplitsing van samengestelde ondernemingen en de waardering van het geheel en de delen
}

\author{
Aberraties van de $1+1=2$-regel
}

Prof. Dr. P.W. Moerland

\section{Inleiding}

Het af- en opsplitsen van conglomeraten lijkt te lonen. Sedert het begin van de jaren tachtig zijn we vertrouwd met allerlei vormen van afslanking en ontvlechting: buy-out, break-up, afstoting, afsplitsing, opsplitsing, enzovoort. In vrijwel alle gevallen wordt daarbij waarde blootgelegd die veelal voordien reeds in potentie aanwezig was, maar die door structurele aanpassingen tot volle wasdom kan komen, enerzijds omdat het reële proces beter loopt, anderzijds omdat de financiële markt daar scherper zicht op krijgt.

Sedert het begin van de jaren tachtig hebben zich in de Verenigde Staten honderden afsplitsingen (spin-offs) voorgedaan, veelal als reactie op een te ver doorgeschoten diversificatie- en conglomeratiegolf in de decennia daaraan voorafgaand. Als schoolvoorbeeld van conglomeraatvorming geldt het Amerikaanse ITT, dat tijdens de derde fusiegolf in de jaren zestig uitgroeide van een telefoonmaatschappij tot een concern met een zeer uiteenlopend activiteitenpakket, daarmee een plaats veroverend in de toptien van Amerikaanse bedrijven. Sinds zijn aantreden in 1979 heeft topman Rand Araskog in vijftien jaar tijd vervolgens 250 business units vervreend. Hetgeen resteerde werd daarna effectief opgesplitst in drie onderdelen: verzekeringen, fabricage en vrije tijd'.

Algemeen wordt de opsplitsing (split-up) van het Britse chemieconcern ICl in 1993 in een geneesmiddelenbedrijf (Zeneca) en een chemiepoot (ICI-chemicals) als de Europese doorbraak van dit fenomeen beschouwd. In ons land hebben onder andere Vendex, KPN en Atag zich intussen opgesplitst, terwijl andere kandidaten wellicht vroeg of laat zullen volgen².
Bij dergelijke opsplitsingen doen zich in de regel aanzienlijke waardevermeerderingen voor. Waar komt dat waardeacres vandaan? Of, met een variant op de bekende synergiesom bij fusies $1+1=3$, hoe kan het dat $1 / 2+1 / 2=2$ ? Deze aberraties van de rekenkunde lijken in strijd te zijn met het bekende value additivity-beginsel uit de financieringstheorie: $1+1=2$.

\section{Optelbaarheid van waarden}

Een van de centrale leerstellingen binnen het vakgebied van de ondernemingsfinanciering betreft het beginsel van de optelbaarheid van waarden. In hun befaamde leerboek 'Principles of Corporate Finance' beschouwen Brealey en Myers het value additivity principle als een van de (zes) basisideeën binnen de leer van de ondernemingsfinanciering, waaromtrent in wijde kring overeenstemming bestaat. Het value additivitybeginsel stelt dat, in een volkomen vermogensmarkt, de waarde van twee gecombineerde activa gelijk is aan de som van hun afzonderlijke waarden ${ }^{3}$. Deze leerstelling houdt onder andere in dat het samenvoegen van twee afzonderlijke ondernemingen op grond van uitsluitend diversificatieoverwegingen op zichzelf geen waarde toevoegt. Ook het omgekeerde is waar: het opsplitsen van een conglomeraat in onderdelen levert op zichzelf geen waarde op, indien althans de diversificatiemogelijkheden voor beleggers

Prof. Dr. P.W. Moerland is hoogleraar Ondernemingsfinanciering en Corporate Governance aan de Katholieke Universiteit Brabant, Tilburg. 
onbeperkt zijn en er overigens sprake is van een perfect werkende vermogensmarkt.

Tegen de achtergrond van deze theoretische leerstelling doen zich in de praktijk waameembare puzzels voor, die zich laten identificeren aan de hand van termen als: diversificatiekorting, break-up valuc, en dergelijke. Deze begrippen suggereren op zijn minst strijdigheid met het value additivity-beginsel, aangezien aan het geheel minder waarde lijkt te worden toegekend dan aan de som der delen van een samengestelde onderneming.

Voor dergelijke afwijkingen van het optelbaarheidsbeginsel zijn mogelijk zowel reële als financiële factoren aan te wijzen. De reële factoren hebben te maken met de omvang en complexiteit van een conglomeraat. De gevaren van tijdrovende beslissingslijnen, verlies aan focus, vertroebeling van prestatie-indicatoren en bestuurlijke inefficiency liggen inmers gedurig op de loer.

De financiële factoren hebben van doen met een mogelijk gebrek aan transparantie en het probleem van informatieasymmetrie.

Hierna wordt nader ingegaan op enkele aspecten van deze reële en financiële factoren, namelijk synergie en anergie (paragraaf 3 ), het agencyvraagstuk (paragraaf 4), en informatieasymmetrie (paragraaf 5). Daarna worden enige empirische bevindingen van financiële aard weergegeven en becommentarieerd. In de slotparagraaf wordt nog een link gelegd met het vraagstuk van corporate governance.

\section{Synergie en anergie}

Fusie- en overnamebewegingen worden veelal gerationaliseerd onder verwijzing naar te behalen synergetische voordelen. Die kunnen bijvoorbeeld betrekking hebben op de operationele sfeer (schaalvoordelen bij inkoop, productie, verkoop), de financiële sfeer (benutting van leencapaciteit), de fiscale sfeer (benutting van compensabele verliezen), enzovoort. Het samengaan van twee ondernemingen zal dan naar verwachting resulteren in toekomstige kasstromen die de gecombineerde kasstromen van de twee afzonderlijke ondernemingen overtreffen. Er zijn voordelen te behalen die door beleggers niet kunnen worden nagebootst.
Een hieraan tegenovergestelde beweging, zoals afstoting. ontvlechting, afsplitsing en opsplitsing kan zijn grondslag vinden in het bestaan van anergie. Vooral bij ondememingen. die zijn samengesteld uit een (groot) aantal ongerelateerde activiteiten kunnen bureaucratie, inertie en koninkrijksvorming dusdanige inefficiënties met zich brengen dat eventuele synergetische voordelen daardoor worden overtroffen, hetgeen de te bereiken kasstromen negatief beïnvloedt ten opzichte van de siluatie waarin de samenstellende delen op zichzelf zouden opereren. Ontmanteling van het geheel en het verzelfstandigen van onderdelen ligt dan in de rede. Het benutten van synergetische voordelen kan op gespannen voet staan met een decentrale vorm van organisatie en besluitvorming ${ }^{4}$. Toch wordt aan deze organisatievorm niet zelden, in enigerlei mate. de voorkeur gegeven, mede uit een oogpunt van het opwekken van voldoende prikkels en tucht.

\section{Agencyvraagstuk}

Het agencyvraagstuk regardeert in essentie het probleem van prikkels en tucht. Tussen divisies en het hoofdkantoor binnen een samengestelde onderneming doen zich gewoonlijk agencyproblemen voor. De doelstellingen van het divisiemanagement en die van de concerntop kunnen op tal van punten divergenties vertonen. Bureaucratische procedures, consolidatie van financiële gegevens en versluiering van goed dan wel slecht management kunnen de prikkel tot excellent presteren wegnemen. dan wel bestraffing van ondermaats presteren doen versloffen ${ }^{5}$. Moral hazard, tree ridership, onderinvesteringen. overinvesteringen en andere vormen van inefficiency zijn inherent aan agencyrelaties en leiden tot agencykosten die de waarde van de samengestelde onderneming negatief kunnen beïnvloeden. Kruislingse subsidiëring van minder goed renderende onderdelen is op den duur fnuikend voor het ondernemerschap in andere goedlopende onderdelen. Beloningssystemen, die in onvoldoende mate aansluiten op verschillen in geleverde prestaties, vanwege mogelijke versluieringen in het registreren en meten terzake, belasten de agencyrelaties van zowel goed als slecht draaiende onderdelen.

Het doorsnijden van dergelijke agencyrelaties door middel van management buy-out, afsplit- 
sing, en dergelijke haalt een streep door dat type agencykosten en is uit dien hoofde waardescheppend. Het is een empirisch vaststaand gegeven dat management buy-outs in de regel bijzonder positief uitwerken op de productiviteit. op de motivatie, en daarmee op het rendement van het desbetreffende onderdeel. Een minder troebele relatie tussen geleverde inspanningen en gerealiseerde uitkomsten kan worden geschraagd door toegesneden optieplannen, biedt de gelegenheid om te werken aan company pride, kortom geeft vleugels aan het ondernemerschap van management en medewerkers. Uit dit alles komt naar voren dat de agencyconfiguratie van ondernemingen van grote invloed is op het prestatievermogen en daarmee op de waarde. Dat is eerder op overtuigende wijze aannemelijk gemaakt door Jensen en Meckling (1976) wat betreft de relatie tussen het management en externe aandeelhouders. Later heeft Jensen (1989) de opkomst van LBO's (leveraged buy-outs) en zelfs het verdwijnen van beursgenoteerde ondernemingsvormen in verband gebracht met agencyproblematiek. Ook voor de interne verhoudingen binnen een concern tussen de top en de onderdelen. en de onderdelen onderling, spelen agencyrelaties een niet onbelangrijke rol. Zij vormen een kernelement van het ondernemingshandelen, tezamen overigens met het informatievraagstuk.

\section{Informatieasymmetric}

Informatieasymmetrie is een belangrijk vraagstuk in het economisch leven. Zo zal de verkoper van een product in het algemeen een informatievoorsprong hebben op de aspirantkoper. Maar ook het omgekeerde kan voorkomen, zoals bij de verkoop van verzekeringen. in welk geval de koper mogelijk beter op de hoogte is van specifieke risico's dan de verkoper. Dit schept een ex ante informatieprobleem, waarbij sprake is van informatieasymmetrie tussen aspirantruilpartners, hetwelk kan leiden tot adverse selection: suboptimaal keuzegedrag in vergelijking met een situatie van symmetrische informatie. Het probleem van adverse selection kan onder omstandigheden zodanig ernstig zijn, dat de markt als coördinatiemechanisme gewoonweg zijn werk niet meer kan doen'. Ook in de verhouding tussen vermogensmarkt en onderneming loert het gevaar van een market break down. Indien de markt een korting toepast bij een aandelenemissie - waarvan de opbrengst is benodigd voor een goed maar in de markt onvoldoende bekend project - verhoogt dit de vermogenskosten, waartegen de investeringsbeoordeling van het project wordt afgezet, mogelijkerwij$z e$ in die mate dat entamering van het project niet langer aantrekkelijk is. Hieruit vloeit dus voort dat het van belang kan zijn om de informatieasymmetrie zoveel mogelijk te beperken. Immers, gebrek aan doeltreffende. betrouwbare en toegesneden informatie vertaalt zich in een hogere rendementseis over het vermogen en daarmee in een lagere waarde van de onderneming.

Het is voor complexe, vertakte ondernemingen minder eenvoudig om die transparantie te bieden - ook al is men van goede wil - dan voor homogene ondememingen. Een samengestelde onderneming is minder goed vergelijkbaar met andere ondernemingen, eenvoudigweg omdat die niet of nauwelijks in een overeenkomstige samenstelling voorhanden zijn. Dat maakt de relatieve beoordeling van het geheel lastig, hetgeen een zelfstandige reden kan vormen voor het plegen van een afslag op de prijs.

Niet zelden beperkt het informatievraagstuk zich niet alleen tot de beleggerszijde, maar strekt het zich ook uit tot de ondernemingsleiding zelf. Ter illustratie diene Thomassen International, dat in augustus 1998 heeft aangekondigd zichzelf te gaan vierendelen, dat wil zeggen zich in vier zelfstandige ondernemingen te gaan opsplitsen. Interimdirecteur Hoogendijk merkte bij die gelegenheid op deze opsplitsing nodig te achten on duidelijkheid te verkrijgen over de winstgevendheid van elk van de onderdelen. 'Dat is nu voor ons onzichtbaar:" zo sprak hij'. Eerder werd vijf keer, zonder gevolg, een beursgang aangekondigd en ketsten besprekingen met General Electric over een totale overname af. Ongetwijfeld heeft het informatieprobleem hierbij een niet te onderschatten rol gespeeld.

\section{Empirische bevindingen}

Het fenomeen diversificatiekorting (diversification discount) slaat niet alleen op conglomeraten, maar evenzeer op holdingstructuren. Zoals bekend berust het Franse systeem van corporate governance op dergelijke structuren. De twee grootste financiële conglomeraten - Suez en Paribas met elk grote aantallen participaties in allerlei ondernemingen, vanwaar de bijnaam 'les 
deux galaxies" - zijn bezig met een herstructureringsprogramma dat erop is gericht om de op hen door de financiële markt toegepaste holdingdiscount te verkleinen. De aandeelhouders van de Compagnie d'Investissement de Paris dringen bij de top van dit conglomeraat aan op maatregelen die ertoe kunnen leiden dat de vigerende discount van 40 procent ten opzichte van de gezamenlijke waarde van de onderdelen kan worden weggewerkt. Enige tijd geleden heeft het conglomeraat Chargeurs als eerste grote Franse groep bekendgemaakt zichzelf op te splitsen in twee afzonderlijk genoteerde bedrijven (media en textiel). eveneens om iets aan de discount te doen ${ }^{x}$.

In de Verenigde Staten is gedegen empirisch onderzoek verricht naar het verschijnsel diversificatiekorting. Daaruit komt in het algemeen naar voren dat gediversifieerde ondernemingen door de beleggers lager worden gewaardeerd dan meer gefocusseerde ondernemingen. Deze laatste kennen een marktwaarde/boekwaarde ratio die ongeveer 15 procent hoger ligt dan bij conglomeraten".

Sommige ondernemingen weten overigens op uitstekende wijze te presteren, ook al vormen ze een conglomeraat. In die gevallen weet de top het management van de onderdelen tot scherp ondernemerschap onder de tucht van dynamische marktprocessen - aan te sturen. Sinds het aantreden van Jack Welch in 1979 heeft hel zwaar gediversifieerde General Electric een gemiddeld rendement van 21 procent dat is 6 procentpunten hoger dan het marktgemiddelde - voor de aandeelhouders opgeleverd. Ook conglomeraten als VEBA in Duitsland en Samsung in ZuidKorea scoorden boven het marktgemiddelde. Er zijn dus stellig gediversifieerde ondernemingen aan te wijzen waar de voordelen van scope, risicospreiding (denk aan faillissementskosten), en dergelijke de genoemde nadelen overtreffen.

Niettemin zijn er bij veel conglomeraten verschijnselen van vervetting en confusie binnengeslopen, waardoor aan de financiële buitenwacht het transparante zicht wordt ontnomen op risico's, het allocatieproces van vermogen, evaluatieen controlemechanismen, enzovoort. Uit empirisch onderzoek in de Verenigde Staten naar de rendementseffecten van afsplitsingen komt naar voren dat dergelijke vormen van herstructurering in het algemeen positief worden ontvangen door beleggers. De onmiddellijke aankondigingseffecten variëren tussen 2 en 5 procent ${ }^{10}$. Over een langere periode gerekend, zowel vóór als na de aankondiging, lopen de buitengewone rendementen van afsplitsingen al gauw op tot enkele tientallen procenten. Ook de opsplitsingen. alhoewel tot nu toe minder in aantal, laten in de regel positieve koersreacties zien ". Een bijkomend voordeel van af- en opsplitsingen is gelegen in de mogelijkheid om nadien meer toegespitste fusie- en overnametransacties te kunnen uitvoeren. Illustratief is de volgende opmerking van financieel directeur Angenent van Vendex International: 'Bij een splitsing zie je toch dat er een betere strategische focus op het bedrijf ontstaat, meer management attentie op wat het bedrijf moet zijin, een veel sterkere commerciële positionering en een veel betere uitgangspositie voor acquisities. We hebben vorig jaar twee grote acquisities van supermarktketens gemist, ondat deze geen onderdeel wilden uitmaken van een concern waarin diensten en non-food zaten. Bedrijven willen zich aansluiten bij een bedrijf dat ze kennen'?

\section{Tot slot}

Af- en opsplitsing van samengestelde ondernemingen zijn ingrepen, die waarde kunnen doen ontstaan, en wel ten gevolge van het elimineren van anergie, het reduceren van agencyproblemen. en het redresseren van informatieve onvolkomenheden. Men hoede zich evenwel voor al te pertinente generalisaties op dit vlak. Hierboven is reeds aangegeven dat er grote conglomeraten zijn, die prima presteren. Het zou interessant zijn om te weten of de financiële markt een dergelijk geheel inderdaad hoger waardeert dan de optelsom der delen. De economie is evenwel geen laboratorium. Zoiets valt immers niet precies vast te stellen zonder zo'n opdeling ook daadwerkelijk door te voeren. Het is overigens heel goed denkbaar dat de ondernemingsleiding daarop een andere visie heeft dan de financiële markt. Geleidelijk aan zijn we aanbeland in een tijdperk. waarin aandeelhouders de ondernemingsbestuurders scherper gaan aanspreken op hun beleid en prestaties $^{13}$. Het rapport van de Commissie Corporate Governance (commissie-Peters) bevat ook een pleidooi in deze richting. Enkele onderwerpen waarop kapitaalverschaffers naar hel oordeel van de commissie invloed zouden moeten kunnen uitoefenen zijn (p. 22 rapport): 
1 het strategisch beleid van de vennootschap, zoals ten aanzien van groeiperspectief, bedrijfstakken waarin zij actief is, het risicoprofiel, het nagestreefde winstniveau, en

2 majeure wijzigingen in de aard en de omvang van de onderneming. Het opsplitsen van de onderneming moet hiertoe worden gerekend. Ik ga ervan uit dat in de nabije toekomst door aandeelhouders aan ondernemingsbestuurders met enige regelmaat indringende vragen zullen worden gesteld over de meest optimale compositie van hun onderneming. Of dat al dan niet een splitsing van het bedrijf dan wel een splitsing van de opinies gaat opleveren zal van geval tot geval moeten blijken.

\section{ITERAT U UR}

Akerlof, G.A., (1970), The market for 'lemons'; quality and the market mechanism, Quarterly Journal of Economics, 84, pp. 488-500.

Berger, P.G. en E. Ofek, (1995), Diversification's effect on firm value, Journal of Financial Economics, 37, pp. 39-65.

Brealey, R.A. en S.C. Myers, (1991), Principles of Corporate Finance, New York, McGraw-Hill.

Copeland, T.E., E.F. Lemgruber en D. Mayers, (1987), Corporate spinoffs: multiple announcement and ex-date abnormal performance, chapter 7 in T.E. Copeland (ed.), Modern Finance and Industrial Economics, New York, Basil Blackwell.

Jensen M.C. en W.H. Meckling, (1976), Theory of the firm: managerial behavior, agency costs and ownership structure, Journal of Financial Economics, 3, pp. 305-360.

Jensen, M.C., (1989), Eclipse of the public corporation, Harvard Business Review, pp. 61-74.

Oijen, A.A.C.J. van, (1997), Besturing door het hoofdkantoor en diversificatie, Heusden, $V a n$ Oijen.

Scheepers, K.W.M. en M.Ch. Staal, (1998), Spin-off, een onderzoek naar de splitsing van Nederlandse beursgenoteerde ondernemingen, Nieuwegein, Van den Boom Groep Uitgeverij.

Schipper, K. en A. Smith, (1983), Effects of recontracting on shareholder wealth, Journal of Financial Economics, 12. pp. 437-467.
Staal, M.Ch. en S.H. Boersma, (1998), De kick-off van de spinoff, Tiidschrift voor Corporate Finance, 3, pp. 14-26.

Weston, J.F., K.S. Chung en J.A. Siu, (1998), Takeovers, Restructuring and Corporate Governance, New Jersey, Prentice Hall.

\section{N O T E N}

1 Ontleend aan Weston, Chung en Siu (1998), pp. 242-243.

2 Voor een interessant overzicht van deze kandidaten raadplege men Scheepers en Staal (1998).

3 Vergelijk Brealey en Myers (1991), pp. 400 en 824. Dit beginsel betreft een situatie, waarin geen synergievoordelen aan de orde zijn.

4 Voor een uitstekende verhandeling over de relaties tussen besturingsconcept en de mate waarin synergetische voordelen kunnen worden behaald, raadplege men van Oijen (1997). Binnen de economische organisatietheorie inzake de boundaries of the firm zijn enkele fundamentele inzichten ontwikkeld over wat wel en niet in de onderneming hoort.

5 Vergelijk Weston e.a., p. 250.

6 Zoals aangetoond door Akerlof (1970) in zijn eminente verhandeling, toegepast op de markt voor tweedehands auto's ('lemons').

7 Ontleend aan NRC Handelsblad, d.d. 19 augustus 1998 en Het Financieele Dagblad, d.d. 19 augustus 1998

8 Deze afslag op de prijs (diversificatie-discount) kan variëren in de tijd. Heden ten dage lijken de bezwaren die aan conglomeraatvorming kleven sterker te gelden dan in de jaren zestig en zeventig.

9 Vergelijk Berger en Ofek (1995).

10 Vergelijk Schipper en Smith (1983) en Copeland, Lemgruber en Mayers (1987).

11 Vergelijk Weston e.a., pp. 242-245 en Staal en Boersma (1998)

12 Lezing van Drs. W.C.J. Angenent RA ter gelegenheid van het door Mercurius georganiseerde congres 'Transforming the Business', d.d. 26 maart 1998 aan de Katholieke Universiteit Brabant, Tilburg.

13 Zo heeft het activistische Calpers (California Public Employees' Retirement System) tezamen met het Council of Institutional Investors het Melville conglomeraat in de Verenigde Staten onder druk gezet om zich door middel van af- en opsplitsing te herstructureren ten einde het beleggingsresultaat op te krikken. Vergelijk Weston e.a., pp. 244-245. 